\title{
Pulmonary artery pressure as a method for assessing hydration status in an anuric hemodialysis patient - a case report
}

\author{
Anne Rudbeck Juhl ${ }^{1 *}$ (D), Jesper Juul Larsen ${ }^{1}$, Kasper Rossing ${ }^{2}$ and Lisbet Brandi ${ }^{1}$
}

\begin{abstract}
Background: Setting the dry weight and maintaining fluid balance is still a difficult challenge in dialysis patients. Overhydration is common and associated with increased cardiac morbidity and mortality. Pulmonary hypertension is associated with volume overload in end-stage renal dysfunction patients. Thus, monitoring pulmonary pressure by a CardioMEMS device could potentially be of guidance to physicians in the difficult task of assessing fluid overload in hemodialysis patients.

Case presentation: 61-year old male with known congestive heart failure deteriorated over 3 months' time from a state with congestive heart failure and diuresis to a state of chronic kidney disease and anuria. He began a thrice/ week in-hospital hemodialysis regime. As he already had implanted a CardioMEMS device due to his heart condition, we were able to monitor invasive pulmonary artery pressure during the course of dialysis sessions. To compare, we estimated overhydration by both bioimpedance and clinical assessment. Pulmonary artery pressure correlated closely with fluid drainage during dialysis and inter-dialytic weight gain. The patient reached prescribed dry weight but remained pulmonary hypertensive by definition. During two episodes of intradialytic systemic hypotension, the patient still had pulmonary hypertension by current definition.
\end{abstract}

Conclusion: This case report observes a close correlation between pulmonary artery pressure and fluid overload in a limited amount of observations. In this case we found pulmonary artery pressure to be more sensitive towards fluid overload than bioimpedance. The patient remained pulmonary hypertensive both as he reached prescribed dry weight and experienced intradialytic hypotensive symptoms. Monitoring pulmonary artery pressure via CardioMEMS could hold great potential as a real-time guidance for fluid balance during hemodialysis, though adjusted cut-off values for pulmonary pressure for anuric patients may be needed. Further studies are needed to confirm the findings of this case report and the applicability of pulmonary pressure in assessing optimal fluid balance.

Keywords: ESRD, Hemodialysis, Pulmonary hypertension, Pulmonary artery hypertension, CardioMEMS, Dry weight, Bioelectrical impedance analysis, Case report

\footnotetext{
* Correspondence: annerjuhl@gmail.com

'Department of Endocrinology and Nephrology, North Zealand University Hospital, Dyrehavevej 29, 3400 Hilleroed, Denmark

Full list of author information is available at the end of the article
}

(c) The Author(s). 2020 Open Access This article is licensed under a Creative Commons Attribution 4.0 International License, which permits use, sharing, adaptation, distribution and reproduction in any medium or format, as long as you give appropriate credit to the original author(s) and the source, provide a link to the Creative Commons licence, and indicate if changes were made. The images or other third party material in this article are included in the article's Creative Commons licence, unless indicated otherwise in a credit line to the material. If material is not included in the article's Creative Commons licence and your intended use is not permitted by statutory regulation or exceeds the permitted use, you will need to obtain permission directly from the copyright holder. To view a copy of this licence, visit http://creativecommons.org/licenses/by/4.0/ The Creative Commons Public Domain Dedication waiver (http://creativecommons.org/publicdomain/zero/1.0/) applies to the data made available in this article, unless otherwise stated in a credit line to the data. 


\section{Background}

Still today, maintaining fluid balance in anuric patients presents a clinical challenge and nephrologists requests a valid method for assessing hydration status. Currently, clinical estimation of dry weight remains the superior method, thus standard of care in assessing hydration status [1]. More exact means of estimating hydration status is of importance, as overhydration is common in hemodialysis patients and associated with increased cardiac morbidity such as systemic and pulmonary hypertension, left ventricular hypertrophy and increased mortality [2-4]. Volume overload itself has been found as an independent risk factor for mortality, even when adjusting for blood pressure [4].

Literature reports of a connection between fluid overload and pulmonary hypertension: Pulmonary hypertension $(\mathrm{PH})$ has been associated with volume overload in end-stage renal dysfunctions (ESRD) patients [4]. The PEPPER-trial investigated pulmonary hypertension in hemodialysis patients by right heart catherization (RHC) [5]. They found a higher prevalence of $\mathrm{PH}$ in the dialysis cohort (77\%) versus the non-dialysis cohort (71\%) and the cause of $\mathrm{PH}$ to depend mainly on fluid overload [5]. Pulmonary hypertension is currently defined as mean pulmonary artery pressure (mPAP) $\geq 20 \mathrm{mmHg}$ combined with an elevated vascular resistance of $\geq 3$ mmHg*liter* $\mathrm{min}^{-1}$ (revised in 2019, previously defined at $\mathrm{mPAP} \geq 25 \mathrm{mmHg}$ at rest measured by RHC) [6].

Though the PEPPER-trial's use of RHC was breaking at the time, it has the limitation of only evaluating pulmonary artery pressure (PAP) before and after dialysis, with no option of monitoring pressure during dialysis. However, this has become possible by a CardioMEMS device, primarily used in the field of cardiology: A pressure sensor implanted into the distal branch of the descending pulmonary artery in a procedure like RHC. Daily pressure readings can be done with home equipment, lasting $10 \mathrm{~s}$ per reading. A physician can then immediately access the pressure reading by a secure database. Besides the measured value of the pulmonary pressure, a waveform for the $10 \mathrm{~s}$ reading is available for qualitative assessment [7].

It seems obvious from the connection between $\mathrm{PH}$ and overhydration that it is of interest to put pulmonary pressure to the test as a method for guidance of fluid status during hemodialysis. The CardioMEMS device holds the potential to be a clinical applicable real-time marker of hydration status during dialysis; however, this is yet to be investigated.

Here we present a case of an anuric hemodialysis patient with an implemented CardioMEMS device, allowing us to invasively monitor pulmonary pressure during the course of hemodialysis.

\section{Case presentation}

61-year-old man was referred to the cardiologist at a highly specialized Danish university hospital, Rigshospitalet, for an evaluation of severe congestive heart failure (CHF) in 2017. He had a history of $\mathrm{CHF}$, dilated cardiomyopati since many years and left ventricular ejection fraction at $20 \%$. About half a year ago, he had an ablation due to tendency to ventricular tachycardia. He was assessed to NYHA class III and had multiple heart failure-related hospitalizations in the past few years. He presented a clinical challenge, as it was difficult to control his fluid balance. He was deemed a candidate for a CardioMEMS device, which was implanted in the fall 2018 without complications. His pulmonary artery pressure was found too high, and subsequently tried lowered by many different kinds of diuretics. However, trying to drain his fluid overload by diuretics turned out to have severe adverse effects:

Kidney parameters increased rapidly

Hypokalemia

Ventricular tachycardia

In a little more than 3 months' time, the patient went from a state of $\mathrm{CHF}$ with diuresis to a state with chronic kidney disease and anuria. He started on a hemodialysis regime with in-hospital dialysis three times weekly through a central venous catheter. After 8 dialysis sessions, he was in start 2019 referred to Department of Nephrology at a bigger university hospital outside Copenhagen, North Zealand University Hospital, Hillerød. This rare combination of having an implanted CardioMEMS device and ongoing hemodialysis gave the possibility to invasively monitor pulmonary pressure in course of the dialysis sessions, and compare the results to clinical assessment and bioimpedance analysis. The sessions were conducted as follows in Table 1. Results are shown in Figs. 1 and 2. Bioimpedance (BIA) was measured by a multifrequency portable wholebody bioimpedance spectroscopy device (Fresenius Medical care). By intradialytic hypotension is understood a decrease in systemic blood pressure along with clinical symptoms as assessed by the responsible dialysis nurse. Pre-dialytic blood samples was planned once weekly. Endpoint was set to be either 10 dialysis, patient death or withdrawal for other reasons.

\section{Discussion and conclusions}

This patient case reports a close correlation between fluid balance and mPAP. It is clearly demonstrated that mPAP decreased over time as the dialysis proceeded and the ultrafiltration volume (UF-volume) increased. The curve representing the second dialysis demonstrates an increase in mPAP as the dialysis have been ended, which can be interpreted as return of the $250 \mathrm{ml}$ extracorporeal blood volume. The pressure decreases again at the final post-dialytic measurement, which we interpret as movement of fluid from the intravascular back to interstitial compartment. MAP remained relatively stable during 
Table 1 Conduction and data of dialysis sessions

\begin{tabular}{|c|c|c|c|}
\hline & & Data & Remarks \\
\hline \multicolumn{2}{|c|}{ Conduction PAP/MAP } & $\begin{array}{l}\text { PAP-readings made at intervals: } \\
\text { - Before beginning of dialysis } \\
\text { - After } 15 \text { min of dialysis } \\
\text { - Once every } 30 \text { min from that point } \\
\text { - At the end of dialysis } \\
\text { - } 15 \text { min after ended dialysis } \\
\text { MAP measured at the same intervals }\end{array}$ & $\begin{array}{l}\text { Mean pulmonary artery pressure (mPAP) } \\
\text { and mean systemic artery pressure (MAP) } \\
\text { is used for discussion in this case report }\end{array}$ \\
\hline \multirow[t]{3}{*}{ Dialysis data } & Session 1 & $\begin{array}{l}\text { Mean UF-rate: } 743 \mathrm{ml} / \mathrm{hr} \\
\text { UF-volume: } 2590 \mathrm{ml} \\
\text { Hemoglobin: } 6.0 \mathrm{mmol} / \mathrm{L} \\
\text { Abumin: } 35 \mathrm{~g} / \mathrm{L} \\
\text { Urea: } 24.4 \mathrm{mmol} / \mathrm{L} \\
\text { Creatinine: } 204 \mathrm{\mu mol} / \mathrm{L} \\
\text { Alkaline phosphatase: } 115 \mathrm{U} / \mathrm{L} \\
\text { Pro-BNP: } 1120 \mathrm{pmol} / \mathrm{L}\end{array}$ & $\begin{array}{l}\text { A total of one PAP reading has been omitted } \\
\text { due to a technical error } \\
\text { Blood samples planned for session } 1,4,7,10 \text {. }\end{array}$ \\
\hline & Session 2 & $\begin{array}{l}\text { Mean UF-rate: } 800 \mathrm{ml} / \mathrm{hr} \\
\text { UF-volume: } 2770 \mathrm{ml}\end{array}$ & \\
\hline & Session 3 & $\begin{array}{l}\text { Mean UF-rate: } 524 \mathrm{ml} / \mathrm{hr} \\
\text { UF volume: } 1600 \mathrm{ml}\end{array}$ & $\begin{array}{l}\text { Final post-dialytic reading has not been obtained } \\
\text { due to patient's compliance, as he was not } \\
\text { admitted and wished to leave the hospital } \\
\text { Two events of systemic hypotension occurred, } \\
\text { that lead the nurse to pause the ultrafiltration. } \\
\text { They are marked by arrows in Fig. } 1\end{array}$ \\
\hline \multicolumn{2}{|c|}{ Patient related data } & $\begin{array}{l}\text { Clinical estimated dry weight: } 86 \mathrm{~kg} \\
\text { Endpoint: The patient died after } 3 \\
\text { dialysis sessions were conducted }\end{array}$ & \\
\hline
\end{tabular}
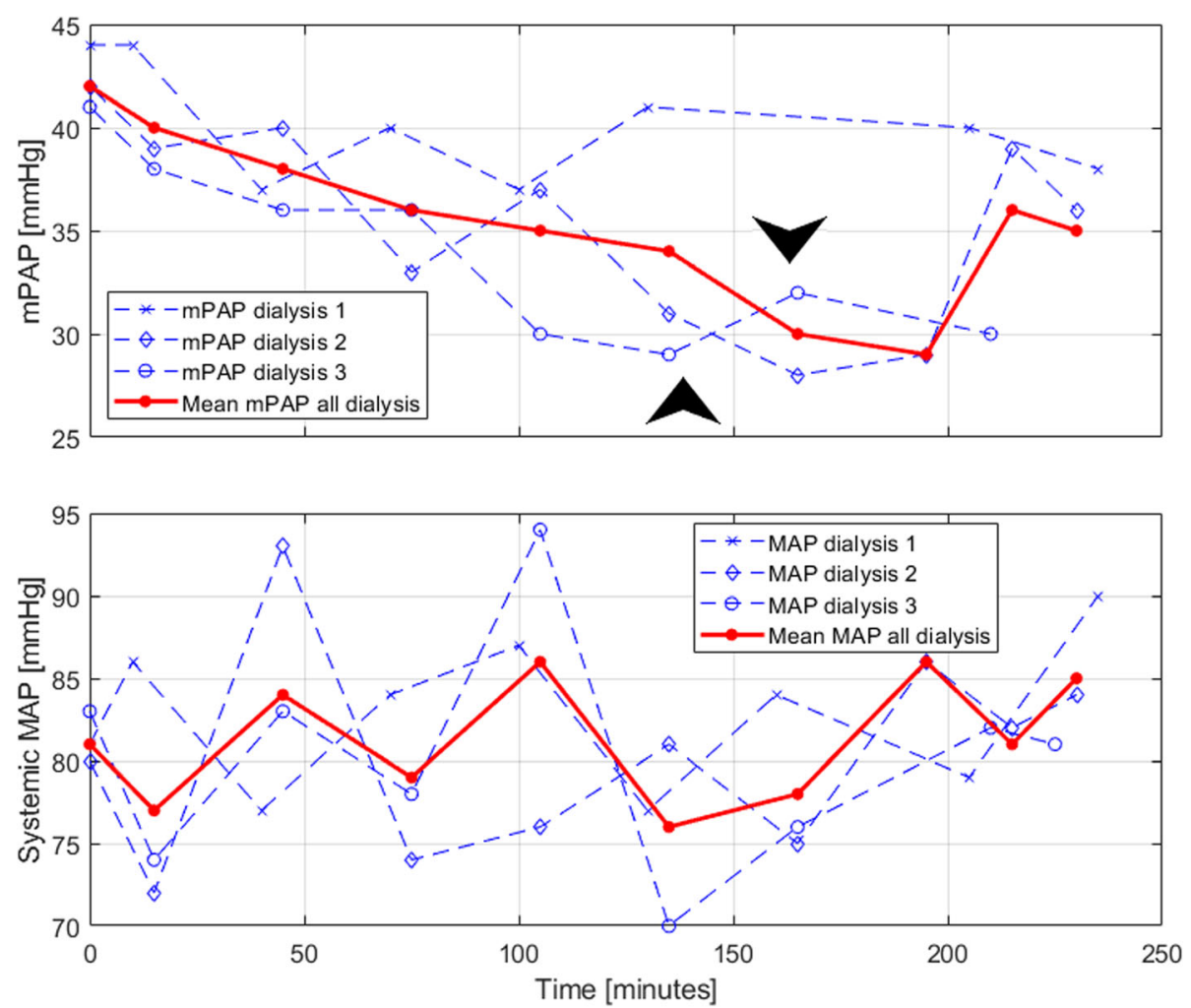

Fig. 1 Mean pulmonary artery pressure (mPAP) and mean arterial systemic blood pressure (MAP) as a function of time during hemodialysis. The arrows marks events of hypotension during dialysis session 3 leading the dialysis nurse to pause ultrafiltration for 5 min per event 


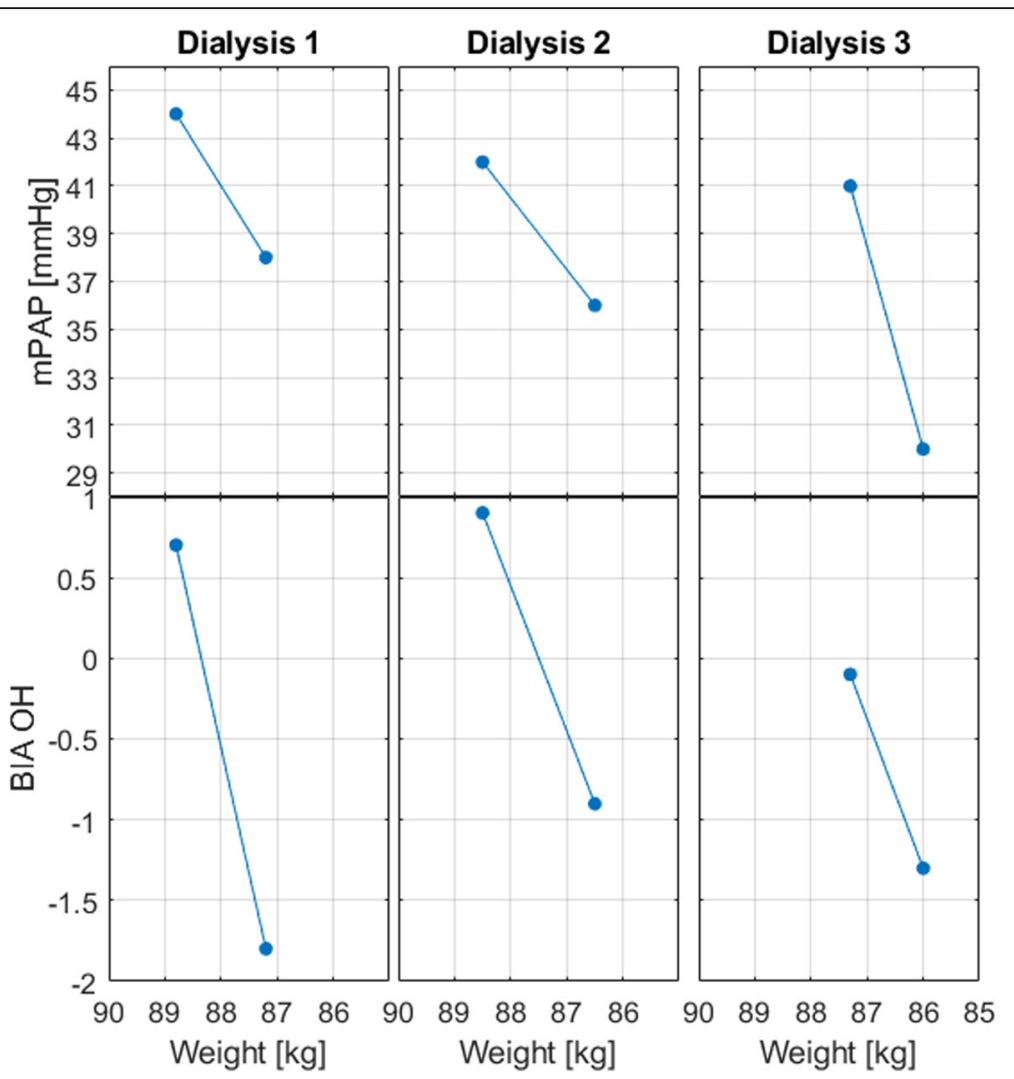

Fig. 2 Mean pulmonary artery pressure (mPAP) and BIA-assessed overhydration $(\mathrm{OH})$ as a function of weight

dialysis. We observed that pre-dialytic mPAP was relatively constant at 44,42 , and $41 \mathrm{mmHg}$ in concordance with the patient's interdialytic weight gain. Thus, we found MPAP to be sensitive towards fluid status, however we cannot safely assume the changes to mPAP to be driven solely by ultrafiltration. The relation between PAP and fluid status is somewhat supported in literature, though the pathophysiology behind PH in ESRD patients is still not fully understood and falls under clinical PH category 5: PH with unclear and/or multifactorial mechanism, including chronic renal failure [5]. The PEPPER-trial suggests a great proportion of $\mathrm{PH}$ in chronic kidney disease (CKD) patients to be related to fluid status, as they found most of the hemodialysis patients suffering from $\mathrm{PH}$ to have post-capillary hypertension [5]. This is usually related to fluid overload and left ventricular dysfunction [8]. The PEPPER-trial found post-dialytic mPAP to be $55 \pm 17 \mathrm{mmHg}$ in their dialysis population [5]. In comparison, the post-dialytic mPAP in this patient was 38,36 and $30 \mathrm{mmHg}$.

Of interest, the patient of this case developed clinical symptoms in terms of two events of hypotension during dialysis, which lead the nurse to pause the ultrafiltration. Neither of these events were associated with pulmonary hypotension; on the contrary, the corresponding mPAP at these two events where 29 and $32 \mathrm{mmHg}$, thus well above the cut-off for pulmonary hypertension for the general population. This raises the question of whether the dry weight was set too low or rather if the patient was unable to compensate for the UF-rate as the pressure becomes nearer that recommended for general population.

To compare with existing methods of assessing hydration status, we estimated hydration status by clinical estimated dry weight and bioimpedance measurement.

The patient reached his prescribed dry weight as the post-dialytic weight for dialysis session 3, with a corresponding mPAP of $30 \mathrm{mmHg}$ still hypertensive by definition. This would seemingly suggests that the patient was still overhydrated, thus dry weight overestimated. The highly elevated pro-BNP levels could somewhat support the patient being overhydrated, however bearing in mind that pro-BNP is strongest as a negative predictive parameter [9]. The cutoff value for pro-BNP needs to be modified according to the severity of renal dysfunction, as pro-BNP undergoes renal clearance. A pro-BNP cut-off at $7200 \mathrm{pg} / \mathrm{ml}(851 \mathrm{pmol} / \mathrm{l})$ has been suggested to discriminate between hemodialysis patients with and without left ventricular dysfunction [9] and our patient's pro-BNP level of $1120 \mathrm{pmol} / \mathrm{l}$ is thus well above. 
We found clinical hydration status to correlate better with PAP than bioimpedance: The BIA-assessed $\mathrm{OH}$ was negative in the end of all the dialysis, thus indicating underhydration even if the patient remained above the prescribed dry weight and mPAP remained elevated. For the final dialysis session, the pre-dialytic BIA-assessed $\mathrm{OH}$ level at -0.11 indicated no need of ultrafiltration, even if the corresponding mPAP at $41 \mathrm{mmHg}$ and body weight did. It seems that the overhydration assessed by BIA were underestimated in all measurements, and inaccuracy of BIA has also been reported in some literature $[1,2]$.

One great limitation to this case report is the limited number of dialysis sessions, which was all that was attainable. This makes it difficult to draw any final conclusions. Keeping this in mind, CardioMEMS seemed superior in assessing hydration status in this patient case, and of interest the patient remained pulmonary hypertensive through intradialytic symptoms and prescribed dry weight, questioning the cutoff value for this anuric patient.

The novelty of the approach of this case report does not allow for many supporting studies. However, a conference abstract on PAP and fluid status supports the findings of this case: The study, based on six patients doing 10-12 dialysis sessions, found a pre-dialytic systolic PAP at $36.6 \pm 10.4 \mathrm{mmHg}$ and concluded that the systolic PAP changes during dialysis mainly depends on fluid status [10].

In conclusion, this case report suggests monitoring pulmonary pressure by the CardioMEMS device could hold exciting prospects as a potential real-time guidance for the nephrologist in assessing fluid status and appropriate dry weight in hemodialysis patients. This case of clinical intradialytic symptoms combined with pulmonary hypertension raises the question of what cut-off should be established for pulmonary pressure in anuric dialysis patients. Further studies are needed to confirm the findings of this case, their applicability in assessing optimal fluid balance and investigate what the cut off for PAP in the dialysis population should be.

\section{Abbreviations}

PH: Pulmonary hypertension; ESRD: End-stage renal dysfunction; RHC: Rightheart catheterization; PAP: Pulmonary artery pressure; CHF: Congestive heart failure; MPAP: Mean pulmonary artery pressure; MAP: Mean artery pressure (systemic); BIA: Multi frequency bioimpedance; $\mathrm{OH}$ : Overhydration; UF: Ultrafiltration; CKD: Chronic kidney disease

\section{Acknowledgements}

We wish to thank mr. Andreas Juhl for his technical help in design of the graphs.
Funding

Not applicable.

Availability of data and materials

All data generated or analysed during this study are included in this published article.

Ethics approval and consent to participate

Not applicable.

\section{Consent for publication}

Written consent for publication has been obtained by the patient's next-ofkin, as the patient died.

\section{Competing interests}

The authors declare that they have no competing interests.

\section{Author details}

'Department of Endocrinology and Nephrology, North Zealand University Hospital, Dyrehavevej 29, 3400 Hilleroed, Denmark. ${ }^{2}$ Department of Cardiology, Rigshospitalet University Hospital, Blegdamsvej 9, 2100 Copenhagen, Denmark.

Received: 15 March 2020 Accepted: 2 July 2020

Published online: 11 July 2020

\section{References}

1. Vasko R, Muller GA, Ratliff BB, Jung K, Gauczinski S, Koziolek MJ. Clinical judgment is the most important element in overhydration assessment of chronic hemodialysis patients. Clin Exp Nephrol. 2013;17(4):563-8.

2. Jaeger JQ, Mehta RL. Assessment of dry weight in hemodialysis: an overview. J Am Soc Nephrol. 1999;10(2):392-403.

3. Covic A, Ciumanghel Al, Siriopol D, Kanbay M, Dumea R, Gavrilovici C, et al. Value of bioimpedance analysis estimated "dry weight" in maintenance dialysis patients: a systematic review and meta-analysis. Int Urol Nephrol. 2017;49(12):2231-45

4. Sinha $A D$, Agarwal R. Setting the dry weight and its cardiovascular implications. Semin Dial. 2017;30(6):481-8.

5. Pabst S, Hammerstingl C, Hundt F, Gerhardt T, Grohe C, Nickenig G, et al. Pulmonary hypertension in patients with chronic kidney disease on dialysis and without dialysis: results of the PEPPER-study. PLoS One. 2012;7(4): e35310.

6. Simonneau G, Montani D, Celermajer DS, et al. Haemodynamic definitions and updated clinical classification of pulmonary hypertension. Eur Respir J. 2019;53:1801913. https://doi.org/10.1183/13993003.01913-2018.

7. Abraham WT, Adamson PB, Bourge RC, Aaron MF, Costanzo MR, Stevenson LW, et al. Wireless pulmonary artery haemodynamic monitoring in chronic heart failure: a randomised controlled trial. Lancet (London). 2011;377(9766): 658-66.

8. Salerno FR, Parraga G, Mclntyre CW. Why is your patient still short of breath? Understanding the complex pathophysiology of dyspnea in chronic kidney disease. Semin Dial. 2017;30(1):50-7.

9. Wang AY. Clinical utility of natriuretic peptides in dialysis patients. Semin Dial. 2012;25(3):326-33.

10. Ojanen Seppo NT, Olli A, Jaako L, Tuomas K. A NOVEL SYSTEM FOR ONLINE MONITORING OF PULMONARY ARTERY PRESSURE DURING HEMODIALYSIS. 55th ERA-EDTA Congress. Copenhagen: Nephrology Dialysis Transplantation; 2018. p. i220.

\section{Publisher's Note}

Springer Nature remains neutral with regard to jurisdictional claims in published maps and institutional affiliations. 